\title{
IDENTIFICACIONES REGIONALES ENTRE LAS ZONAS FRONTERIZAS DE COMITÁN, México, y Huehuetenango, Guatemala. 1824-2001
}

\author{
Regional Identifications between the Border Areas of Comitan, Mexico, \\ and Huehuetenango, Guatemala. 1824-2001
}

\author{
Carine Chavarochette
}

Resumen: Las grandes etapas históricas y políticas de los siglos $X I X$ y XX, que podemos delimitar con sucesos tales como los tratados de límites entre México y Guatemala, la Revolución mexicana, los refugiados guatemaltecos, el movimiento zapatista y el incremento de los flujos migratorios centroamericanos, modificaron las identidades de las poblaciones fronterizas. Estos acontecimientos dejaron huellas profundas y transformaron la región del sureste chiapaneco y del noroeste de Guatemala. En este artículo se trata de definir cómo estas poblaciones viven y piensan las decisiones nacionales; cómo el Estado nacional las singulariza, cómo se singularizan a su vezy, por fin, cómo la tenencia de la tierra y la presencia de una frontera internacional favorecen una identificación singular. Así, la identidad fronteriza puede ser un concepto que permite analizar las identidades locales, nacionales y transnacionales.

Palabras clave: fronteras, prácticas religiosas, relaciones culturales, identidad cultural, peregrinaciones, ciudadanía.

Abstract: The big historical and political stages of the XIXth and XXth century that we can delimit with such events as the agreements of limits between Mexico and Guatemala, the Mexican Revolution, the Guatemalan refugees, the movement zapatista and the increase of the migratory Central American flows, modified the identities of populations. These events left deep fingerprints and transformed the region of Chiapanecan south-east and Guatemalan northwest. In this article, it is a question of defining how these populations live and think the national decisions; how the national State distinguishes them and how they are distinguished in turn and finally, how the possession of the land and the presence of an international border favor a singular identification. Thus, the concept of identity "boundary", can be selfidentities to analyze local, national and transnational.

Keywords: borders, cultural identity, cultural relations, religious practices, pilgrimages, citizenship.

Carine Chavarochette, doctora en antropología histórica por la Universidad París 7-Diderot. Investigadora del Centro de Investigaciones y Estudios Documentales sobre las Américas del Centro Nacional Francés de Investigaciones Científicas (CREDA-CNRS) en París. Temas de especialización: antropología, historia, Chiapas, Guatemala, Arizona, mayas, fronteras, antropología simbólica, peregrinaciones, etnicidad, propiedad agraria, conflictos agrarios, políticos, gestión del agua. Correo electrónico: carinechavarochette@gmail.com.

Enviado a dictamen: 18 de enero de 2013.

Aprobación: 07 de febrero de 2014.

Revisiones: 3. 


\section{Introducción}

E la época prehispánica existía una relación muy estrecha entre el sureste de lo que hoy es el estado de Chiapas y los pueblos del valle de Huehuetenango, aunque éstos, debido a las distintas influencias externas y al hecho de pertenecer a grupos etnolingüísticos diferentes, no formaban una entidad político-económica única. Esta región fronteriza ubicada en el límite del Imperio azteca operaba como punto de encuentro entre culturas diferentes: México y América Central.

Durante la época colonial, y en las postrimerías del siglo XIX, cuando se fijan las actuales fronteras político-administrativas, esta zona actualmente fronteriza —entre La Trinitaria y Huehuetenangocontaba con espacios territoriales disponibles y abiertos hacia diferentes poblaciones. Allí convivieron tanto indígenas como españoles o ladinos. ${ }^{1}$ Los conflictos entre indígenas, ladinos y criollos ${ }^{2}$ comenzaron a acentuarse en el siglo XVIII, cuando se produjo la recuperación demográfica indígena y, posteriormente, también con las reformas liberales del siglo XIX que modificaron la tenencia de la tierra (Lovell, 1990; Davis, 1997; Chavarochette, 2011).

Durante el período colonial, los límites administrativos entre la provincia de Chiapas y la Alcaldía Mayor de Totonicapán fueron semejantes al límite internacional que acordaron los gobiernos mexicano y guatemalteco en el siglo XIX ${ }^{3}$ (De Vos, 1997). Ya entonces, esta región no sólo hacía las veces de región-frontera civilizadora y militar, sino que también operaba como un punto de intercambio comercial entre la Nueva España y Guatemala. Antes de la llegada de los españoles, tojolabales y chujes habitaban un territorio común (Piedrasanta, 2009; Ruz, 1982; Navarrete, 1982). Sin embargo, la colonización no destruyó el contacto existente entre chujes, tojolabales y zapalutas. ${ }^{4}$ Así, estos diferentes grupos habrían ocupado la región repartiéndose las tierras y el poder.

Desde su creación en 1882, y hasta 2001, la frontera entre Chiapas y Guatemala osciló entre dos modelos. El primero es el descrito por el estadounidense
Frederick Turner en torno a la noción de frontier: una frontera móvil y abierta. ${ }^{5}$ El segundo es el establecido a partir de un concepto que permite entender los procesos del área: border, una frontera límite o línea divisora. Durante la mayor parte del tiempo - excepto durante una parte de la Revolución mexicana y de la guerra civil guatemalteca - la que predominó fue una visión asociada al concepto de frontier. Solamente a principios de la década de los ochenta del siglo pasado, época de la guerra civil guatemalteca y de la llegada masiva de los refugiados a México, la concepción que habría prevalecido fue la de border —en el espíritu de numerosos refugiados el mismo acto de atravesar el límite internacional les ofrecía la protección del Estado mexicano- La frontera móvil aún sigue existiendo hoy en día como consecuencia de la migración hacia Estados Unidos y Canadá. El inmigrante centroamericano la atravesaba en los años noventa buscando el mito de un nuevo El Dorado y pensando llegar lo antes posible a la frontera norte. En esta época, el sellamiento de la frontera en la carretera de Comitán en dirección a San Cristóbal de Las Casas dejó en claro que los controles migratorios no estaban ubicados cerca de la línea divisora, sino fuera de la zona fronteriza y, además, en el Istmo de Tehuantepec. Así, la noción de border no se traducía necesariamente como proximidad a la línea.

Las relaciones entre México y Guatemala se establecen y se apoyan en lazos históricos y en costumbres seculares. La identidad de las poblaciones fronterizas ha estado directamente condicionada por los acontecimientos históricos y las decisiones políticas y el establecimiento de la frontera internacional ha determinado tanto la resistencia como las representaciones de los habitantes de esta zona.

A través de esta investigación diacrónica en la zona fronteriza entre el municipio de La Trinitaria y el departamento de Huehuetenango, que abarca los siglos XIX y XX, interrogo distintos conceptos de frontera existentes: la frontera política - la frontera internacional percibida por los gobiernos-, la frontera étnica, que se analiza a través de la tenencia de la tierra y de las romerías transfronterizas, y la frontera social entre agricultores y no agricultores. ${ }^{6}$ ¿Qué significa ser 
fronterizo? ¿Cómo la tenencia de la tierra confrontada con una frontera política causa una identificación especial?

La primera parte del trabajo aborda la ciudadanía y las decisiones políticas que afectaron a las poblaciones fronterizas entre 1824 y 2001. La segunda parte trata de presentar la manera de compartir identificaciones por parte de estas poblaciones, las cuales están ligadas a la tierra, a su posesión y a los conflictos asociados entre 1882 y 2001. Estas identificaciones se perciben a través del estudio de una romería transfronteriza del año 2001 (ver mapa 1).

\section{Decisiones políticas y población fronteriza}

En 1824, México, con el apoyo de las élites de San Cristóbal de Las Casas, incorporó la región de Chiapas a su territorio. Desde 1824 hasta 1882, las autoridades mexicanas y guatemaltecas intentaron definir infructuosamente un límite preciso entre los dos países. Se debe subrayar que los dos gobiernos no ejercían su soberanía en esta zona. Habría que esperar hasta 1882 para que firmaran el primer tratado, aunque sólo el siguiente, suscrito en 1895, marcaría definitivamente los límites entre los dos Estados. ${ }^{7}$ El l de abril de $1895^{, 8}$ ambos países sellaron el tratado definitivo que fijó la frontera que conocemos hoy en día; de tal manera que quedó establecida una frontera política entre México y Guatemala.

Sin embargo, México, un país con un Estado fuerte y estructurado, descuidó durante un siglo su frontera sur y sólo la redescubrirá a finales del siglo XX debido a dos sucesos: el flujo de refugiados guatemaltecos y la presión estadounidense para la creación del TLCAN.

\section{Establecimiento de la frontera y tenencia de la tierra}

En el siglo XIX, en México, y con mayor fuerza en Guatemala, los liberales promulgaron leyes que limitaban o terminaban con la propiedad colectiva de la tierra; instauraron así el predominio de la propiedad privada y una noción de progreso sustentada en el desarrollo de una agricultura de exportación. Los pueblos mayas no contaban con medios suficientes para acceder a la propiedad privada y, en Guatemala, las autoridades políticas procuraron conservar la jerarquía social basándose en un modelo de segregación. La oligarquía debía basar su riqueza y poder en la propiedad de la tierra y contar al mismo tiempo con una mano de obra sumisa y barata para desarrollar una agricultura de exportación. A diferencia de Guatemala, la política liberal mexicana - por ejemplo, a través de las leyes Lerdo de 1856 - tenía por objeto que los indígenas se diluyeran en la nación emergente. Para ello, se perseguía acabar con un régimen de propiedad colectiva que aparecía como un obstáculo. En este último aspecto México y Guatemala presentan diferencias, aun cuando Chiapas constituye un caso particular en México. En realidad, en Chiapas, se ha considerado históricamente a la población indígena como una reserva de mano de obra servil y, a la vez, como una vía para acaparar las tierras más baratas (Viqueira y Ruz, 1998).

Si retomamos la terminología de Turner (1893) y su frente pionero, podemos decir que durante siglos la actual región de Nentón, ubicada al noroeste del departamento de Huehuetenango, en Guatemala, se mantuvo como una reserva de tierras. En el siglo XIX dicha zona, hasta entonces marginada y alejada de los centros de poder y de poblamiento, comenzó a convertirse en centro de interés. Tras el repunte demográfico indígena en el siglo XVIII y la presencia cada vez mayor de ladinos e inmigrantes europeos deseosos de poseer grandes propiedades de tierra, se empezó a cuestionar a la población chuj. En el siglo XIX, el crecimiento demográfico obligó a las personas a desplazarse para encontrar nuevas tierras y como consecuencia otras poblaciones indígenas - jacaltecos, akatecos- y ladinas se instalaron en esta región. La población chuj —originaria de San Mateo Ixtatán o de San Sebastián Coatán- cultivaba tierras de las cuales no contaba necesariamente con un título de propiedad, sino con un derecho de facto o un usufructo, y practicaba una agricultura de alternancia entre tierras altas y bajas. Posteriormente, en 1876, fecha de creación del municipio de Nentón - formado en respuesta a la 
migración importante de ladinos del municipio vecino de Jacaltenango, quienes acudían ahí desde hacía años para que pastara su ganado-, la dotación de tierras de esta región de diversidad étnica se vio fuertemente disminuida. Los chujes, así como los jacaltecos, que hasta entonces contaban con terrenos para realizar cultivos agrícolas de temporada, o para la caza y la pesca, se vieron obligados a competir con ladinos y alemanes, quienes habían llegado en busca de nuevas tierras. A partir de 1860, la inmigración europea - principalmente alemana - hacia la región estudiada cobró importancia. Las familias de los finqueros lograron poseer tierras en ambos lados de la frontera; hicieron pasar así los intereses personales, familiares y locales sobre los intereses nacionales.

Paralelamente, se redujeron las tierras comunales del pueblo de San Mateo Ixtatán; con ello, se beneficiaron las aldeas chujes y ladinas del municipio recién creado. Ni siquiera la compra de tierras pertenecientes al Estado consiguió solucionar el problema de acceso a la tierra.

Las comunidades chujes, zapalutas y tojolabales no estaban necesariamente al tanto de las limitaciones jurídicas que les habían impuesto legalmente las autoridades de México y Guatemala. Las tierras ubicadas lejos del centro del pueblo y en las que éstos habían vivido con anterioridad, o que simplemente cultivaban durante una parte del año, aparecían como de su pertenencia, al menos desde un punto de vista simbólico. Simultáneamente, algunos finqueros hacían desaparecer los mojones que delimitaban los terrenos indígenas para poseer más tierras. Una consecuencia de esta inseguridad jurídica fue que los pueblos mayas atacaron a los finqueros con las mismas armas: títulos de propiedad, agrimensores y reconocimiento de límites, e incluso recurriendo a la violencia - como los chujes en el siglo XIX $-{ }^{9}$ y, por otro lado, insistiendo en el hecho de poseer derechos sobre una parcela determinada debido a que sus antepasados también la habían cultivado.

Con algunos documentos coloniales ${ }^{10}$ es posible acreditar, además, la existencia de acuerdos entre los pueblos mayas de la zona relativos a la delimitación de sus territorios respectivos. Durante todo el período colonial, a las autoridades y a la población les fue muy difícil deslindar y saber de manera precisa cuáles eran los límites de las propiedades. La creación de la frontera internacional y las problemáticas territoriales de cada Estado no hicieron sino acentuar dicha situación.

La dificultad para establecer un límite claro entre México y Guatemala en esta región fue en cierta medida consecuencia de la cuestión agraria. En el momento en que ambos gobiernos intentaban fijar sus soberanías y fronteras respectivas, las comisiones encargadas de las mediciones topográficas debieron enfrentarse tanto a particulares y finqueros como a la población indígena. Además, se vieron en la obligación de establecer una frontera que considerara los intereses locales y la propiedad agraria histórica. Así, la delimitación de la frontera internacional se insertó en un entramado preexistente; los latifundistas y la población indígena hicieron lo posible para que ésta les favoreciera.

\section{La época de los levantamientos armados y de las tensiones económicas}

La Revolución mexicana no ayudó a consolidar el sentimiento de pertenencia nacional de los chiapanecos. Las luchas revolucionarias fueron aprovechadas sobre todo por las élites como una forma de perpetuar los poderes existentes (García de León, 1991). Los antiguos revolucionarios que lideraban el Estado mexicano aceptaron los intereses de las grandesfamilias chiapanecas conservándolos intactos. Durante la Revolución, la porción de la frontera observada funcionó como un espacio de refugio para las diferentes tropas y como un lugar importante de contrabando de armas y de caballos. Con frecuencia, las autoridades mexicanas reprochaban a sus homólogas guatemaltecas el no haber combatido de manera eficaz el contrabando y haber protegido a las tropas rebeldes chiapanecas. El límite internacional siguió siendo una frontera artificial en esta región.

Incluso después de la Revolución mexicana, ninguno de los dos Estados mostró mayor interés en delimitar visualmente dicha frontera. Los mojones eran escasos. Frente a la falta de soberanía nacional, las diferentes poblaciones fronterizas siguieron ejerciendo su influencia." 
A partir de 1930 - y en esto podemos apreciar la voluntad del joven Estado mexicano de afirmar su soberanía - el gobierno mexicano decidió aumentar el control de su frontera sur. Guatemala, viendo en ello una manera de perjudicar a sus pequeños comerciantes itinerantes, rechazó el cierre de la frontera.

Años más tarde, la llegada masiva de refugiados guatemaltecos generó trastornos en la política mexicana. Dicho movimiento migratorio contribuyó, entre 1981 y 1983, al desarrollo de una política de seguridad nacional en México. Además de intensificar el control estatal de la frontera, el problema de los refugiados provocó una mayor toma de conciencia sobre la existencia de la misma. Este drama humano marcó una ruptura en la percepción que México y los mexicanos tenían sobre el límite fronterizo. A partir de ese momento, el Estado decidió tomar medidas para establecer la frontera sur e imponer un límite territorial sólido entre ambos países.

La presencia de los refugiados guatemaltecos ocasionó una mayor militarización del Estado mexicano y en especial de Chiapas. Entre 1981 y 1983, las incursiones sucesivas del Ejército guatemalteco en Chiapas - región a la que se consideraba como refugio de guerrillerosoriginaron un aumento de la vigilancia en la frontera sur por parte del Estado mexicano. No obstante, y al contrario de Estados Unidos, el Estado mexicano nunca ha condenado los movimientos revolucionarios centroamericanos.

La presencia de refugiados guatemaltecos en el sureste de México hizo resurgir el problema fronterizo entre ambos países. A partir de entonces, el gobierno mexicano decidió imponer su soberanía en una región que desde su anexión, en 1824, había permanecido al margen del poder estatal. La presencia de dichos refugiados provocó, además, el resurgimiento del conflicto agrario. El préstamo ${ }^{12}$ a los refugiados de terrenos privados o pertenecientes a la Iglesia y la aceptación por parte de éstos de sueldos bajos suscitaron el descontento de la población chiapaneca. En este contexto, y frente a las presiones estadounidenses, en 1984, el Gobierno decidió desplazarlos hacia regiones no fronterizas con Guatemala (Freyermuth y Hernández, 1992; Kauffer, 2000).
Los refugiados constituyeron un nuevo tipo de inmigrante diferente a los inmigrantes temporales. La primera medida que tomaron las autoridades mexicanas tuvo por objeto controlar este flujo migratorio mediante una política establecida desde finales de los años ochenta del siglo pasado. La proliferación de casetas migratorias en el sur del estado y, a veces, incluso, la presencia de agentes migratorios dentro de los campamentos de refugiados realizando actividades de censo pusieron de manifiesto la permeabilidad histórica de dicha frontera. Por su parte, el Ejército mexicano cobró mayor presencia a lo largo de la frontera. Paralelamente, la construcción de nuevos caminos que posibilitaran la llegada de ayuda internacional favoreció el desarrollo de la región otorgándole una mayor accesibilidad. Esta nueva infraestructura consolidó las relaciones comerciales que se habían practicado históricamente entre los habitantes fronterizos. El desarrollo de la región incentivó las relaciones transfronterizas entre las diferentes comunidades.

Asimismo, a partir de los años ochenta, las invasiones de tierras en Chiapas se volvieron cada vez más frecuentes (Benjamin, 1995). Por un lado, desde hacía varias décadas se esperaba la aplicación de una ampliación de los ejidos; ha ocurrido a veces que a dos pueblos colindantes se les ha atribuido una misma parcela (Van der Haar y Lenkersdorf, 1998; Chavarochette, 2011). Por otro lado, frente a la falta de tierras disponibles, en algunos pueblos, los habitantes decidieron comenzar a cultivar las tierras desocupadas. Por último, los finqueros dejaron sin explotar tierras de las cuales habían conseguido un certificado de no afectación agraria, esgrimiendo su supuesta utilización. La crisis zapatista de 1994 fue una consecuencia de esta disfunción (SRA, exp. 23/21467, 23/14708, 23/15955) Además, la reforma del artículo 27 de la Constitución de 1917, que suprimió el carácter inalienable de los ejidos, aumentó nuevamente el valor de la propiedad privada del mismo modo en que lo hicieron los gobiernos liberales del siglo XIX. Así, frente a la incapacidad de los Estados para iniciar una reforma agraria, no es de extrañar que indígenas o ladinos pobres de Guatemala y Chiapas se hayan decidido a adquirir los títulos de 
propiedad privada de las tierras que cultivaban. Tanto en Guatemala —donde los habitantes de un pueblo chuj tuvieron que esperar hasta 1980 para lograr la aplicación de un acuerdo gubernamental de 1915 que reconocía el derecho de propiedad de las tierras que cultivaban-, como en Chiapas - donde en la década de los noventa los tojolabales todavía no obtenían las parcelas que se les habían otorgado a través de la Reforma Agraria a finales de los años treinta - el Estado obstaculizó la redistribución de la tierra, ya sea por negligencia, por lentitud administrativa, o debido al peso de grupos oligárquicos.

Con el movimiento zapatista, surgido el 1 de enero de 1994, se reforzó la presencia del Estado mexicano y del Ejército en el estado de Chiapas. Al contrario de lo ocurrido durante la guerra civil guatemalteca, la población civil mexicana que huyó hacia Guatemala fue escasa. Los controles migratorios aumentaron en la frontera entre México y Guatemala, si bien el paso entre ambos países no ofrecía mayores dificultades para la población fronteriza. Esta última logró franquear los puestos de control gracias al conocimiento que ha tenido del terreno, así como de las tradiciones y modo de vida mexicanos.

\section{La época de las migraciones internacionales}

El conflicto zapatista y la guerra de baja intensidad, con que respondió el Ejército mexicano contribuyeron a la proliferación de controles militares en el estado de Chiapas. Al mismo tiempo, el incremento en años recientes del número de migrantes centroamericanos y sudamericanos ${ }^{13}$ indocumentados ha producido un aumento de los controles migratorios por parte de México. Los controles de las autoridades migratorias se sumaron a los retenes militares y a los de la policía judicial. Una zona hasta entonces aislada y alejada de las preocupaciones nacionales se vio convertida en poco tiempo en centro de interés internacional.

En los años noventa, la autoridad migratoria mexicana instaló puestos de control al borde del camino, lo que denominó el "sellamiento" de la frontera. Esta denominación hace referencia a la limitación fronteriza internacional creada por el gobierno mexicano a fines del siglo XIX. Nuevamente, esta zona limítrofe aparece como una región aparte. El Estado mexicano, al permitir que la frontera se desplazara como mejor le pareciera, estaba reconociendo la particularidad de esta región. La frontera internacional se materializa en territorio mexicano a más de cuarenta kilómetros de la frontera que acordaron ambos Estados a fines del siglo XIX. Los controles migratorios no sólo son cada vez más numerosos en Comitán, sino que además se intensifican en el Istmo de Tehuantepec, en el estado de Oaxaca.

A finales del siglo XX, la situación limítrofe ha sido alterada nuevamente. La frontera entre Guatemala y México estaría aproximándose una vez más al concepto de border. Los controles ya no se sitúan en el Istmo de Tehuantepec ni en la carretera panamericana de Comitán - al menos en lo que respecta a las patrullas de control móvil o "volantas"-, sino a lo largo de la frontera. Estados Unidos ejerció su influencia sobre los diferentes gobiernos mexicanos para que éstos incrementaran el control en la frontera sur, intentando limitar así el flujo de inmigrantes indocumentados hacia la frontera norte (Sandoval, 1997; Castillo, Lattes y Santibañez, 1998). Paralelamente, también en la zona sur, se ha agudizado el tráfico de drogas, y con controles policiales y militares se busca cerrar la frontera.

\section{Identificaciones agrarias y fronterizas}

\section{La frontera que idearon los gobiernos y la frontera vivida por la población}

La población de esta región fronteriza ha practicado históricamente la movilidad y el desplazamiento por diferentes razones: en busca de nuevas tierras, de relaciones comerciales o de una agricultura de alternancia entre tierras templadas y frías, debido a sus prácticas religiosas y culturales, y aun al exilio político.

Los guatemaltecos, que tras la ratificación del Tratado de 1882 vieron cómo sus tierras y pueblos pasaban a formar parte del territorio mexicano, tuvieron un plazo de un año para escoger su nacionalidad. Se les dio la posibilidad de conservar su nacionalidad de origen 
aunque vivían en México o de optar por la nacionalidad mexicana.

En el caso de Chiapas, el Tratado de Límites con Guatemala, que opera simultáneamente como ley interna para los Estados que lo celebraron, define de manera precisa que los individuos domiciliados en territorios transferidos a la soberanía de México, y que no hubiesen optado por su nacionalidad de origen, deberán ser considerados como mexicanos (SRE México, IV/337/46, p. 4).

Los guatemaltecos que vivían en el estado de Chiapas, al no conocer el contenido de esta ley, pasaron a ser mexicanos sin saberlo. Concretamente, en los archivos de la Secretaría de Relaciones Exteriores de México consta que las autoridades mexicanas declararon como ciudadanos mexicanos a guatemaltecos que realizaron peticiones para conservar su nacionalidad original después de 1883. Durante todo el siglo XIX, período de establecimiento de la frontera, parte de esta población cambió sucesivamente de nacionalidad.

Lo anterior nos hace pensar que desde la firma del Tratado de Límites de 1882, el modo de vida de los habitantes fronterizos no ha registrado cambios muy importantes. Ellos continuaban pasando una y otra vez por el nuevo límite internacional sin preocuparse realmente por la delimitación establecida por los gobiernos respectivos. Más aún, algunos de estos habitantes ni siquiera sabían cuál era su verdadera nacionalidad ya que no todos contaban con documentos de identificación.

Al ser incapaces de acreditar una nacionalidad determinada cuando los controlaban en el paso fronterizo, podía ocurrir que las autoridades los obligaran a quedarse del otro lado de la frontera. Niños nacidos en México de padres guatemaltecos, e instalados en el estado de Chiapas desde fines del siglo XIX, carecían de documentos que acreditaran su derecho a la nacionalidad mexicana.

Años más tarde, la aplicación de la Reforma Agraria en el estado de Chiapas hizo resurgir el problema migratorio. En 1932, el gobierno mexicano de Lázaro
Cárdenas promulgó una ley de inmigración. Esta última se hacía necesaria ante la aplicación de la Reforma Agraria, especialmente en Chiapas. En los hechos, una gran parte de los campesinos sin tierras que vivían en la zona fronteriza eran de origen guatemalteco y, a pesar de haber vivido por largos años en Chiapas, no tenían nacionalidad mexicana o les era difícil probar que sí la tenían. En agosto de ese mismo año, los gobiernos guatemalteco y mexicano decidieron reunirse en México para intentar resolver el tema migratorio. Según un censo de población realizado en aquella época por las autoridades mexicanas, cuarenta mil habitantes de Chiapas ignoraban de qué nacionalidad eran. Por su parte, el gobierno guatemalteco estimó que en su territorio habitaban quince mil mexicanos.

El resultado de esta reunión consistió, por un lado, en otorgar a la población fronteriza -fuera o no comerciante- un estatus especial; se le dio facilidades para pasar de un país al otro con un salvoconducto especial —en lugares específicos, como es el caso del pueblo guatemalteco de Gracias a Dios, desde el cual se puede acceder a Nentón y a San Mateo Ixtatán-. Por otro lado, se decidió facilitar el desplazamiento individual de pequeños comerciantes que transportaran su propia mercancía. Así, en 1935 se estableció la realización de un control demográfico de la población chiapaneca que tendría por objeto determinar la población mexicana y guatemalteca y, por ende, quiénes podían aspirar a recibir tierras y quiénes no.

Aunque no era necesario haber nacido en México para acceder a derechos ejidales, sí debía poder acreditarse la nacionalidad mexicana.

En los municipios de la zona fronteriza, gran cantidad de campesinos declaraban ser mexicanos sin ser capaces de probarlo. Muchos guatemaltecos vivían en el estado de Chiapas desde finales del siglo XIX, y a comienzos de los años treinta del siglo XX aún no contaban con documentos que acreditaran su calidad de mexicanos. Una gran cantidad de pequeños campesinos guatemaltecos no se enteró nunca de que, como consecuencia del Tratado de Límites, debían inscribirse en los registros mexicanos. Ninguna de esas familias ni sus descendientes hicieron valer posteriormente su 
derecho a la nacionalidad mexicana. El censo de 1930 arrojó un total de 16385 guatemaltecos. No obstante, como el método de conteo sólo consideró como tales a aquellas personas que estuvieran inscritas en los registros para extranjeros, se ha sugerido que los guatemaltecos ascendían más bien a 25000 (Zorrilla, 1984: 719).

Una de las consecuencias de la Revolución mexicana fue la destrucción de numerosos documentos del Registro Civil. Cuando se hizo necesario establecer la cantidad de ciudadanos mexicanos, las autoridades se vieron forzadas a recurrir a los registros parroquiales, pero las actas de bautizo no mencionaban el lugar de nacimiento ni la nacionalidad de los padres de los inscritos.

Sin embargo, en 1937, el gobierno mexicano decidió que los acuerdos concluidos con Guatemala, en 1932, sobre los inmigrantes guatemaltecos en el estado de Chiapas en realidad eran informales. Como México no conseguía establecer la nacionalidad de todos los habitantes de Chiapas, el proceso de regularización de los indocumentados se hizo lento. Ese mismo año, en algunas plantaciones del Soconusco se registró hasta el 95\% de trabajadores guatemaltecos, incluidos caporales.

La nueva Constitución, promulgada el 5 defebrero de 1917, modificó las normas referentes a la definición de la ciudadanía mexicana. En 1941, la Comisión Demográfica mexicana concluyó sus labores de recuento. En los acuerdos del 3 de marzo de 1941, se otorgó la calidad de población migratoria a la mayor parte de la población del sureste de Chiapas; se afirmó que la mayoría de los habitantes eran mexicanos y que aquellos que se consideraran guatemaltecos tenían la nacionalidad mexicana (Zorrilla, 1984: 724). El Gobierno intentó resolver por esta vía el problema de los inmigrantes guatemaltecos instalados desde hacía mucho tiempo en Chiapas. Por su parte, el problema de los trabajadores indocumentados siguió existiendo.

Históricamente, los habitantes de esta región fronteriza han gozado de un estatus especial. En un documento de 1940 titulado "Tratado de límites y migración entre México y Guatemala” (SRE III/2399/14), fueron establecidas condiciones migratorias particulares para los habitantes fronterizos. En el texto fueron consideradas zonas fronterizas la región sureste de Chiapas y la región noroeste de Guatemala. Las ciudades y pueblos de Comitán, Zapaluta - La Trinitaria-, Motozintla, Unión Juárez, Tuxtla Chico, Frontera Comalapa y Tapachula delimitarían la zona fronteriza mexicana. Por el lado guatemalteco, las localidades limítrofes elegidas fueron Nentón, Santa Ana Huista, Huixtla, Tacaná, Malacatán y Coatepeque. A los habitantes de estas áreas les estaría permitido residir en el país vecino e ir y volver al otro país durante cuatro días sin necesidad de obtener un salvoconducto específico, como sería el caso de los otros residentes mexicanos y guatemaltecos. Este plazo de cuatro días se podía "prolongar por medio de una solicitud verbal a la autoridad aduanera correspondiente" (SRE III/2399/art.14). Los gobiernos guatemalteco y mexicano reconocieron de esta manera el carácter particular de esta región y el hecho de que sus habitantes estuvieran acostumbrados a pasar de uno a otro país - un "pase" de 72 horas vigente hasta 2010 era muestra de la continuidad de dicha política-. Paralelamente, las autoridades tuvieron la intención de crear un carné de identificación especial, gratuito y válido por un período determinado, que estaría reservado exclusivamente para los habitantes de la frontera entre ambos Estados (SRE III/2399/14 art. 14, 18 y 19).

Cabe la posibilidad de que, por un lado, más que una manera de facilitar los desplazamientos de los habitantes fronterizos hacia uno u otro país, este documento sólo tuviera como propósito el control de los flujos migratorios. Por otro lado, se indicaba que el Gobierno de acogida no podría inscribir a estas personas en el registro de extranjeros y que no les estaría permitido residir permanentemente en el país, sino sólo por un máximo de seis meses seguidos.

\section{Romerías transfronterizas}

En la región estudiada, los conflictos agrarios entre campesinos, finqueros, indígenas, municipalidades y Estado trastornan tanto el espacio físico como el social. Las diversas crisis políticas y sociales chiapanecas del 
siglo XX han provocado en la población respuestas específicas, como peregrinaciones y apariciones sobrenaturales.

La peregrinación a Santa Ana Huista ha sido la fiesta más importante de la región fronteriza y ha atraído mayoritariamente a población ladina del lado mexicano. Esta romería, que se lleva a cabo en Semana Santa, es una muestra de una devoción popular común que la creación del límite internacional no ha podido borrar. Aunque de hecho los años de guerra civil impidieron el desplazamiento de los peregrinos, el aumento de la presencia del Estado en la frontera no ha impedido a los peregrinos mexicanos dirigirse al país vecino. Allí se pudo ver, durante la investigación, que han compartido durante tres días la vida de sus vecinos guatemaltecos, han intercambiado comidas y han celebrado juntos. Un peregrino precisó:

Toda el área geográfica aquí, Nentón, Santa Ana [Huista], Jacaltenango [...] comparte el mismo sentimiento de pertenencia cultural, se le percibe con la veneración del Cristo a Santa Ana Huista. Los fronterizos guatemaltecos de Nentón explican la presencia de mexicanos a Santa Ana Huista, por el hecho que la cultura por el otro lado es la misma, antes las tierras pertenecían a Guatemala. La visita [a los santuarios] forma parte de nuestra misma historia (entrevista a Felipe, Nentón, 1999).

Algunos atestiguaron que las numerosas familias jacaltecas de este pueblo eran de origen chiapaneco.

Se observó que, durante su recorrido, esta peregrinación transfronteriza atravesaba gran cantidad de fincas. Para los finqueros y comerciantes de La Trinitaria, ésta representaba una manera de visitar a los vecinos con el objeto de afianzar las relaciones con ellos, según las entrevistas realizadas en el año 2000. Además, la romería permitió que pequeños campesinos, empleados y cualquier persona sin recursos de La Trinitaria y sus alrededores se reunieran al menos una vez al año con los trabajadores de las fincas fronterizas.

Existen otras celebraciones transfronterizas. En 1995, los habitantes de Comitán crearon una nueva peregrinación tras la desaparición de una imagen sagrada en el pueblo guatemalteco fronterizo de San Antonio Huista. Los comitecos decidieron ir a buscar una nueva imagen a Chetumal y propusieron a los habitantes de San Antonio Huista traer - venderles exactamente - una estatua de la Virgen de Guadalupe. La peregrinación nació debido al recorrido que hicieron varias decenas de familias de Comitán para acompañar el traslado de esta nueva estatua hacia Guatemala. Así, se ha creado una nueva manifestación religiosa fronteriza que agrupa a chiapanecos de la región de Comitán.

El flujo de vehículos totalmente se paró. Durante dos horas, la frontera fue cerrada, el tiempo para que pudimos hacer los honores correspondientes, ambos himnos nacionales fueron jugados a la frontera. [...] Nos dimos la bienvenida, dieron la bienvenida a la Virgen que acababa de pasar en territorio guatemalteco hacia las diez de la mañana (entrevista a Armando Rodríguez, diciembre de 2000).

La peregrinación a San Antonio Huista surgió menos de un año después del inicio del movimiento zapatista en Chiapas. En ese momento, muchos chiapanecos, ladinos e indígenas sufrieron una desestructuración al verse confrontados por la violencia política, la represión y los enfrentamientos agrarios. Armando Rodríguez prefirió no señalar cuál era la ocupación de los fieles: dueños de tierras, ganaderos o gente oriunda de la ciudad. ${ }^{14} \mathrm{Como}$ fuera, el surgimiento de esta peregrinación pareció mostrar nuevamente que en los momentos precisos en los que las identidades chiapaneca y mexicana atravesaban por una crisis, la población fronteriza recurrió justamente a prácticas religiosas y culturales ubicadas al otro lado de la frontera, en Guatemala. Estos fieles no quisieron seguir la peregrinación del Cristo Negro de Esquipulas, que todos los años en el mes de enero ha atraído hacia Guatemala a grandes cantidades de mexicanos de todo el país. Prefirieron en cambio apropiarse de un nuevo culto, de un nuevo territorio religioso.

Al igual que en el caso de la peregrinación a Santa Ana Huista, la de San Antonio Huista también es una 
manifestación religiosa centrada en el entorno familiar que se lleva a cabo en un contexto colectivo de tipo regional: todos los fieles son habitantes del estado de Chiapas. Los peregrinos se desplazan junto a su estructura familiar. Estas dos peregrinaciones revelan la religiosidad popular de la población fronteriza chiapaneca.

Por otra parte, estos habitantes eran capaces de compartir una misma identificación fronteriza, una identificación común a todos los habitantes localizados entre Comitán y Huehuetenango. En este artículo se trata de probar que esta identificación fronteriza se articula con la identificación étnica, nacional, regional o campesina, especialmente en tiempos de crisis. El límite entre México y Guatemala no separó tanto las dos identidades nacionales, de manera que puede afirmarse que existe una identificación singular y fronteriza. Sin embargo, las barreras no dejan de existir. Así, dentro de un mismo pueblo nos encontramos con fronteras intra e interétnicas, ya sean confesionales o imaginarias.

Considero que la identidad fronteriza no está vinculada al territorio sino a la transformación de éste. La afirmación de una identidad fronteriza muestra cómo, a través de estas prácticas culturales, tanto indígenas como ladinos carentes de tierras responden simbólicamente a las políticas agrarias y a las decisiones políticas y económicas de las cuales son víctimas. La creación de una nueva peregrinación transfronteriza en 1995 es un elemento sintomático.

Por lo que respecta a la romería a San Mateo Ixtatán, tuve la oportunidad en 2001 de caminar con los peregrinos de La Trinitaria - México- hasta San Mateo Ixtatán - Guatemala - y de observar tanto los rituales como los lugares atravesados. El recorrido escogido por los peregrinos en el año 2001 me puso de manifiesto el sistema de propiedad agraria de la región, es decir, el de las antiguas fincas y grandes propiedades, pero también el de las tierras cultivadas y administradas comunitariamente, representadas a través del sistema mexicano de los ejidos. La memoria histórica de los tojolabales en aquel año se fundamentaba en un pasado lleno de prestigio, aunque también de dominación y de sufrimiento - evidenciado por el sistema de fincas- compartido con los habitantes mestizos de La Trinitaria. ${ }^{15}$

Las peregrinaciones más importantes realizadas bajo la dirección de autoridades religiosas zapalutas (Adams, 1988) revelan los límites del territorio tojolabal junto con los de otros grupos étnicos vecinos. Me refiero a Fredrik Barth (1969) y a su concepto de frontera étnica. Este autor considera la etnicidad como un proceso social dinámico y no como la expresión de una tradición arcaica. Estas romerías destacan ante todo los territorios presentes o míticos de los tojolabales y revelan, además, los eventos históricos que vivieron estas poblaciones - especialmente la usurpación de tierras y el sometimiento en las fincas-, así como su movilidad incesante. La peregrinación de los tojolabales es además el acto de veneración de una migración o su legitimación. Este ciclo anual de peregrinación les permite deambular entre las fronteras antiguas y recientes de los centros de poder (Garma y Shadow, 1994; Coleman y Eade, 2004). Es la superposición del rito agrario y de la veneración mítica, relacionada con una migración en la que se basa la identidad de este grupo de peregrinos. Además, la reconstrucción identitaria de los tojolabales por medio de la construcción religiosa del territorio recalca su nomadismo.

En un contexto de globalización, pero también de crisis políticas nacionales y locales, activar, crear o recrear rituales expresa una relación con el otro de dominación, sumisión o miedo, pero también de cooperación. Para usar los términos de identificaciones relacionales establecidas por categorías que propone Rogers Brubaker (2001), la peregrinación tojolabal del año 2001 participó de estos dos tipos de identificación: por un lado, puso de relieve la sumisión como peones hacia los finqueros $\mathrm{y}$, después, como ejidatarios dependientes a menudo de los antiguos dueños; por otro lado, subrayó la pertenencia a un grupo de personas que compartían los atributos de un grupo étnico, regional y social.

\section{A modo de conclusión}

Los tratados que México y Guatemala suscribieron en 1882 y 1895, la Revolución mexicana, la guerra civil 
guatemalteca, el éxodo de refugiados guatemaltecos a comienzos de los años ochenta del siglo XX, e incluso el movimiento zapatista, constituyen eventos que marcaron, modificaron y dejaron sus huellas en la región fronteriza ubicada entre Comitán y Huehuetenango. Los conflictos han sido, en el sentido más amplio, el motor de las relaciones sociales en la región.

Desde fines del siglo XIX hasta los años treinta del siglo XX, los ganaderos vivían en ambos lados de la frontera y sus animales pastaban indistintamente en uno u otro Estado. A finales del siglo XX, medio siglo después de concluir el primer Tratado, la población fronteriza seguía viviendo como si aquel límite internacional no existiera y en general se negaba a pagar los impuestos aduaneros. Ante una presencia del Estado todavía insignificante, se desarrollaron relaciones privilegiadas y estrechas entre dicha población.

Por el contrario, durante la guerra civil guatemalteca, las poblaciones fronterizas mexicana y guatemalteca tomaron verdadera conciencia de la frontera. A través del acto de atravesar un límite internacional en busca de asilo político, los refugiados le confirieron materialidad a la frontera entre México y Guatemala. Para éstos, la frontera constituyó en sí misma el elemento que definía su condición, su nueva identificación.

En última instancia, por medio de la romería estarían reafirmando su identidad social como agricultores, la que se habría visto alterada sobre todo debido a una emigración cada vez más marcada hacia Estados Unidos. La peregrinación estudiada revela una identidad fronteriza basada en lo local - la región y la religión- que, si bien es más estructurante que las demás, es una identificación "por defecto". Las diferentes poblaciones que viven en este territorio han definido su espacio instalando sus propias fronteras. La historia de la región está centrada en la cuestión agraria y las peregrinaciones no son sino otra prueba de ello.

La población fronteriza ha vivido y experimentado eventos políticos, sociales y económicos similares: las fincas, el sometimiento, la violencia política, los problemas de acceso a la tierra y, desde finales del siglo XX, la migración hacia Norteamérica. Sin embargo, al mismo tiempo existen diferencias: el Estado mexicano es más estructurado y menos segregacionista que el guatemalteco.

Esta porción de la frontera México-Guatemala entre Comitán y Huehuetenango no es étnica ni militar - al contrario que en otros países latinoamericanos, porque no hubo guerras entre los dos Estados-, ni tampoco física - no la demarca un río-, sino que está ligada a la cuestión de la tenencia de la tierra. Finalmente, no es sino la población fronteriza la que ha objetado su trazado y la que ha determinado su demarcación.

En esta región, la noción de frontera y la de posesión de la tierra están íntimamente relacionadas. Allí cohabitan al mismo tiempo una tradición no escrita de posesión temporal del suelo generalmente ligada a su uso, y un tipo de propiedad proveniente del derecho romano. Aunque casos como éste son conocidos y frecuentes en diferentes lugares del mundo, la importancia de esta región en particular radica en la interferencia de la cuestión agraria en la noción de frontera.

\section{Notas}

"Al inicio de la colonización, el término "ladino" hacía referencia al indígena que hablaba castellano; sin embargo, la población mestiza - no indígena y no criolla-, hoy en día lo denomina mestizo - $\mathrm{O}$ noindígena- por oposición al indígena.

${ }^{2}$ Durante la colonización, el término hacía referencia al descendiente de españoles nacido en el continente americano. Hoy en día, en Guatemala se usa para un grupo limitado de familias guatemaltecas poderosas que reivindican una identidad criolla.

${ }^{3}$ Me refiero aquí solamente a la porción estudiada en este artículo, no a las otras regiones fronterizas.

${ }^{4}$ Habitantes de la antigua localidad de Zapaluta de la provincia de Los Llanos, en el actual territorio de La Trinitaria.

${ }^{5}$ Concepto también utilizado por de Vos (1993) para describir la frontera sur de México.

${ }^{6}$ Para el concepto de "frontera cultural", ver Fábregas (2003). 
7 El 12 de agosto de 1882 se firman los acuerdos preliminares en Nueva York. El 27 de septiembre de 1882, en México, ambos Estados firman el Tratado de Límites. Además de cederle Chiapas y el Soconusco a México, Guatemala pierde 27949 kilómetros cuadrados de territorio, es decir, el 6\% de la superficie nacional, recibiendo a cambio sólo 3105 kilómetros cuadrados. En 1884, el gobierno guatemalteco decidió obstaculizar directamente in situ el trazado de los límites internacionales impidiendo a los agrimensores la realización de las mediciones topográficas. Como consecuencia de lo anterior, en 1892 la situación se encontraba en un estado extremadamente frágil (SRE México L/E/2039, años 1898 a 1911, paquete 10; Zorrilla, 1984; De Vos, 1993 y 2010). La cuestión del establecimiento de la frontera entre ambos países sólo pudo concluirse de manera definitiva en 1895.

${ }^{8}$ La firma del nuevo tratado en abril de 1895 clarifica la situación de Soconusco. La región de Ayutla y sus alrededores es cedida a Guatemala, mientras que Motozintla vuelve a México. El sucesor de Barrios, Reyna Barrios (1892-1898), bajo la presión de Estados Unidos, acepta firmar el Convenio de León-Mariscal, en el cual Guatemala reconoce que no podrá ejercer su soberanía sobre Chiapas. Para más datos sobre el caso de Petén y la Guerra de los Mapas, ver Valdez (2008).

${ }^{9}$ Ver el caso de la finca Gracias a Dios en 1873, SRE 1873, núm. 30, o de la hacienda Tierra Negra, núm. 38, Secretaría de Gobernación de Chiapas, Límites con Guatemala, año 1881, y SRE 24/6/25.

${ }_{10}$ Núm. 37, Secretaría de Gobernación de Chiapas, Límites con Guatemala, año 1854.

${ }^{11}$ Además, el área fronteriza de Chiapas sirvió de refugio para la oposición guatemalteca que huía de la dictadura de Cabrera en los años veinte y de la del general Ubico a finales de los treinta.

${ }^{12}$ En 1994, todos los predios puestos a disposición de los refugiados guatemaltecos fueron invadidos y quienes se quedaron en México buscaron otros lugares para instalarse.

${ }^{13}$ En las entrevistas que realicé entre 1999 y 2001 en el municipio de Nentón se mencionó también la presencia de bolivianos en la región fronteriza - en el municipio de Nentón-.

${ }^{14}$ Trabajo de campo en 2000.

${ }^{15}$ Para más información a este respecto, ver Chavarochette (2004 y 2011).

\section{Referencias bibliográficas}

Adams, Walter E., (1988) "Religious practices of southeastern Chiapas and Tzeltal-Tojolabal interaction", en Campbell, Lyle, The Linguistics of Southeast Chiapas. Provo, Utah, NWAF/Brigham Young University.

Barth, Fredrik, (1995) [1969] Les Groupes ethniques et leurs frontières. París, PUF.

Benjamin, Thomas Louis, (1995) Chiapas tierra rica, pueblo pobre. Historia política y social. México, Grijalbo.

Brubaker, Rogers, (2001) "Au-delà de l'«identité»", en Actes de la Recherche en Sciences Sociales. Vol. 4, núm. 139, pp. 66-85.

Castillo Manuel, Ángel, Alfredo Lattes y Jorge Santibáñez (coords.), (1998) Migración y fronteras. México, COLMEX/Colegio de la Frontera Norte/ALS.

Chavarochette, Carine, (2004) "Le pèlerinage des indiens tojolabal (Chiapas-Mexique). San Mateo Ixtatán (Guatemala) ou comment un rite agricole et des relations interethniques participent à la structuration de l'ethnicité. tojolabal", en Cahiers des Amériques Latines. Núm. 44, pp. 23-39.

Chavarochette, Carine, (2011) Frontières et identités en terres mayas. Mexique-Guatemala XIXe-XXIe siècle. París, L'Harmattan.

Coleman, Simon y John Eade (eds.), (2004) Reframing pilgrimage. Cultures in motion. Londres/Nueva York, Routledge.

Davis, Shelton Harold, (1997) La tierra de nuestros antepasados. Estudio de la herencia y la tenencia de la tierra en el altiplano de Guatemala. Guatemala, CIRMA, Plumsock Mesoamerican Studies.

De Vos, Jan, (2010) Vienen de lejos los torrentes. Una historia de Chiapas. Chiapas, Umbrales/CONECULTA Chiapas.

De Vos, Jan, (2002) "La frontera sur y sus fronteras: una visión histórica”, en Kauffer, Edith (ed.), Identidades, 
migraciones y género en la frontera sur de México. San Cristóbal de Las Casas, Chiapas, ECOSUR, pp. 49-67.

De Vos, Jan, (1997) Vivir en frontera. La experiencia de los indios de Chiapas. México, CIESAS.

De Vos, Jan, (1993) Las fronteras de la frontera sur. México, UJAT/CIESAS.

Fábregas Puig, Andrés, (2003) Reflexiones desde la tierra nómada. México, Universidad de Guadalajara/El Colegio de San Luis.

Freyermuth Enciso, Graciela y Rosalva Aida Hernández Castillo, (1992) Una década de refugio en México. Los refugiados guatemaltecos y los derechos humanos. México, CIESAS.

García de León, Antonio, (1998) Resistencia y utopía. México, Era.

García de León, Antonio, (1991) Ejército de ciegos “testimonios de la guerra chiapaneca entre carrancistas y rebeldes" 1914 1920. México, Ediciones Toledo.

Garma Navarro, Carlos y Roberto Shadow (coords.), (1994) Las peregrinaciones religiosas: una aproximación. México, UAM Iztapalapa.

Kauffer, Edith, (2000) Les réfugiés guatémaltèques au Chiapas. Le retour du peuple du maïs, un projet politique. París, L'Harmattan.

Lovell, George W., (1990) Conquista y cambio cultural: la Sierra de los Cuchumatanes de Guatemala 1500-1821. Antigua, Guatemala, CIRMA.

Monteforte Toledo, Mario, (1997) La frontera móvil. México, UNAM/Naciones Unidas/Ministerio de Cultura y Deportes/Ediciones Don Quijote.

Navarrete, Carlos, (1982) "Las rutas de comunicación prehispánica en los Altos Cuchumatanes. Un proyecto arqueologico y etnohistorico", en Ruz, Mario Humberto (ed.), Los legítimos hombres. México, UNAM.

Piedrasanta Herrera, Ruth, (2009) Los chuj. Unidad y rupturas en su espacio. Guatemala, Armar.

Ruz, Mario Humberto y Antonio Gómez Hernández, (1992) Memoria, los tojolabales y las fincas. Testimonios. México, UNAM/UNACH.
Sandoval, Juan Manuel, (1997) "La región fronteriza de México en la perspectiva de la seguridad estadounidense", en Bovin, Philippe (coord.), Las fronteras del Istmo. México, CEMCA/CIESAS, pp. 155161.

Toussaint, Monica, (1997) “Justo Rufino Barrios la Unión Centroamericana y el conflicto de límites MéxicoGuatemala", en Bovin, Philippe (coord.), Las fronteras del Istmo. México, CEMCA/CIESAS, pp. 91-96.

Turner, Frédérick J., (1963) [1893] La frontier dans l'histoire des États-Unis. París, PUF.

Van der Haar, Gemma y Carlos Lenkersdorf (comps.), (1998) Testimonios de una comunidad tojolabal, San Miguel Chiptik. México, Siglo Veintiuno.

Valdez Gordillo, Mario E., (2008) "Chiapas: de la "Guerra de los mapas" de 1895 a las regiones de frontera. Un análisis desde la perspectiva de la geografía política y la geografía histórica“, en Takwa. Núm. 14, pp. 59-87.

Valdez Gordillo, Mario E., (2006) Desencuentro y encuentro de fronteras: el Petén guatemalteco y el sureste mexicano: 1895 1949. Guadalajara, Ediciones de la Noche/Universidad Intercultural de Chiapas/Universidad de Ciencias y Artes de Chiapas.

Viqueira,Juan Pedroy Mario Humberto Ruz(eds.),(1998) Chiapas los rumbos de otra historia. México, UNAM/ CIESAS/CEMCA/Universidad de Guadalajara.

Webre, Stephen, (1989) La sociedad colonial en Guatemala: estudios regionales y locales. Guatemala, CIRMA/PMS.

Zorrilla, Luis G., (1984) Relaciones de México con la República de Centro América y Guatemala. México, Editorial Porrúa.

\section{Archivos consultados}

Secretaría de Gobernación de Chiapas, México (SGC). Secretaría de Relaciones Exteriores, México (SRE). Secretaría de la Reforma Agraria, México (SRA). Archivo General de Centroamérica (AGCA). 


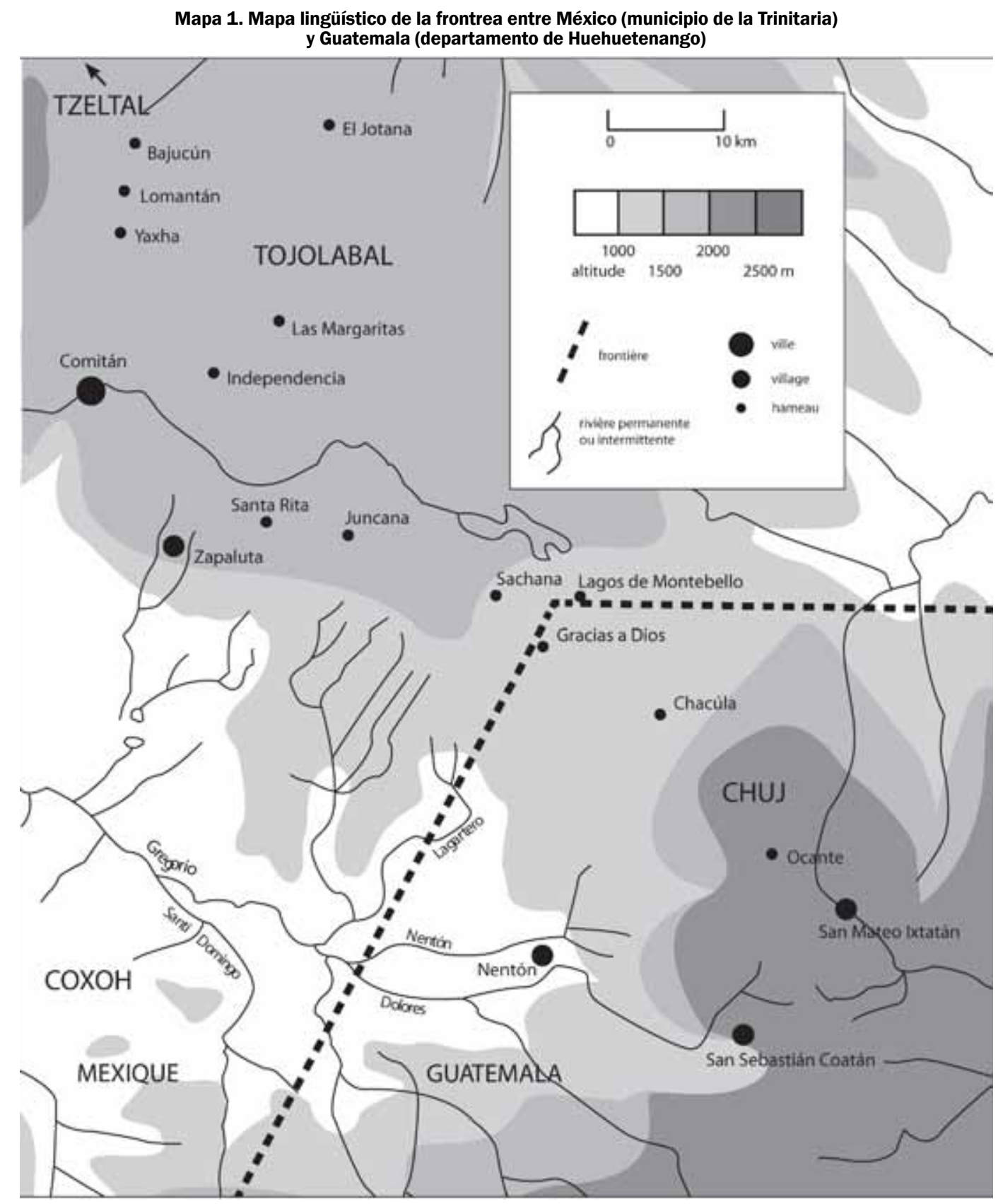

Fuente: Lyle Campbell (1988). 